\title{
CONTROL OF GAMETE RELEASE IN FUCOID ALGAE: SENSING HYDRODYNAMIC CONDITIONS VIA CARBON ACQUISITION
}

\author{
Gareth A. Pearson.' Ester A. Serrăo,' and Susav H. Brawley \\ Department of Plant Biology and Pathology: University of Maine, Oromo. Maine 04469-5722 USA
}

\begin{abstract}
We investigated the environmental factors providing signals for gamete release in fucoid algae, with a particular focus on the inhibitory effect of water motion. The release of gametes by Fucus distichus occurred in still water under high light and was associated with the depletion of dissolved inorganic carbon (DIC) in tide pools isolated from the ocean during daytime low tides. Diurnal patterns of gamete release that lasted for $2-3 \mathrm{~d}$, as in natural populations, were found in receptacles cultured in a $12 \mathrm{~h}$ light: $12 \mathrm{~h}$ dark photoperiod under calm conditions or in a simulated tidal regime. Constant light disrupted the diurnal component of release, however, suggesting that an endogenous circadian periodicity was absent. The effects of increased [DIC] on cultured receptacles under calm conditions were similar to the inhibitory effects of high water motion; both conditions reduced release in several species from both tide pool and intertidal habitats. Bicarbonate concentration, rather than carbon dioxide, or carbonate, was shown to be the component of the DIC system most closely correlated (inversely) with gamete release in the intertidal fucoid Pelvetia compressa. The hypothesis that gamete release is triggered by DIC depletion in the unstirred boundary layer during periods of low water motion in the light was further supported by experiments with $P$. compressa. These showed that gamete release was not inhibited by high water motion when DIC was absent. In the same experiments, high water motion inhibited release at 2 and $20 \mathrm{mmol} / \mathrm{L}$ DIC, confirming that the sensitivity of gamete release to water motion is DIC dependent. The ability of fucoid algae to couple physiological processes (e.g., photosynthesis) with life history events (gamete release) allows external fertilization to occur under favorable hydrodynamic conditions, and may contribute greatly to reproductive success in organisms inhabiting periodically turbulent environments.
\end{abstract}

Key words: external fertilization success; fucoid algae: gamete release (spanming): hydrodynamic conditions; inorganic carbon: intertidal; reproductite ecology.

\section{IVTRODUCTION}

Water motion is one of the most important variables affecting the reproductive biology of organisms with external fertilization. Experimental studies with artificially induced spawning demonstrate that fertilization success declines as water velocity increases (Pennington 1985, Levitan et al. 1992). Modeling studies of organisms releasing gametes into turbulent flows predict fertilization efficiencies of $<1 \%$ (Denny 1988 , Denny and Shibata 1989). Moreover, the increased probability of fertilization in areas such as surge channels with limited water exchange (Denny et al. 1992) may be counteracted by small-scale shear forces acting on gametes and zygotes (Mead and Denny 1994). Studies of natural spawning events also suggest that higher than average water velocities (Petersen 1991, Babcock et al. 1992, Oliver and Babcock 1992, Petersen et al.

Manuscript received 17 October 1996: revised 26 June 1997; accepted 8 July 1997.

'Present address: U.C.T.R.A.. Universidade do Algarve. Campus de Gambelas, 8000 Faro, Portugal.

Present address: School of Marine Sciences. 5722 Deering Hall. University of Maine. Orono. Maine 04469-5722 USA.
1992) or changes in current direction (Lasker et al. 1996) can reduce fertilization success.

The best chance for organisms to increase external fertilization success in turbulent environments is to avoid releasing gametes during periods of high water motion. We recently demonstrated that high water motion inhibits gamete release in fucoid algae (Serrão et al. 1996). Natural populations of Fucus vesiculosis L. from the Baltic Sea and $F$. distichus L. (formerly $F$. distichus ssp. distichus; Rice and Chapman 1985) from intertidal pools cach release gametes coincident with periods of low water motion, and have high levels of fertilization success (generally $>95 \%$; Pearson and Brawley 1996, Serrão et al. 1996).

Reproductive activity (c.g., gametogenesis, gamete release, larval release) in marine species is commonly entrained by environmental factors with circannual, lunar, or semilunar rhythms, or is triggered by specific temperatures or photoperiods (reviewed by Korringa 1947, Giese and Kanatani 1987, Neumann 1987, Santelices 1990, Brawley and Johnson 1992). The formation of reproductive structures (receptacles) in fucoids is triggered by daylength (Bird and McLachlan 1976), and gametogenesis in red algae occurs in re- 
sponse to long or short days, depending upon the species (Guiry and Cunningham 1984). The highly synchronized cycles of gametogenesis in some species of the brown algal genus Dictyota (Williams 1905, Phillips et al. 1990) are a response to lunar cycles in one species, Dictyota dichotoma, and can be entrained by artificial moonlight in culture (Müller 1962). Gamete release occurs with a lunar or semilunar periodicity in a wide range of marine taxa (e.g., corals [Babcock et al. 1986]; reef-dwelling fishes [Robertson et al. 1990]; fucoid algae [Brawley 1992]).

Synchronization of gamete release with tidal or lunar cycles can enhance fertilization success, which can be profoundly affected by changes in the rate of gamete release at time scales of minutes (e.g., Babcock et al. 1992). Therefore, proximate environmental cues acting over shorter time scales play a crucial role in "finetuning" gamete release. Endogenous chemical cues in holothuroids have been implicated in synchronizing gametogenesis in concert with environmental factors ( $\mathrm{Ha}-$ mel and Mercier 1996). Spawning pheromones coordinate gamete release in several species, including some echinoids (Beach et al. 1975, Miller 1989) and brown algae (Lüning and Müller 1978; reviewed by Maier and Miiller 1986, Maier 1993). Spawning activity in some sea urchins and mussels is stimulated by metabolites produced during phytoplankton blooms, thus ensuring an adequate food supply for planktonic larval stages (Starr et al. 1990, 1993). The ability to sense water motion as a proximate signal coordinating gamete release, however, has the twofold advantage of (1) enhancing synchrony of release, and (2) ensuring that release occurs only during hydrodynamic conditions favorable for fertilization (Pearson and Brawley 1996, Serrão et al. 1996).

In this paper we investigate how water motion is perceived by fucoid algae. Fucus distichus L. is monoecious, and is limited to high intertidal pools (Chapman and Johnson 1990). Gamete release follows a circatidal periodicity, and occurs largely during low tides that fall between $\sim 1000$ and 1400 Eastern Standard Time (EST) (Pearson and Brawley 1996). Photosynthetic carbon acquisition by tide pool algae causes a depletion of inorganic carbon and an increase in $\mathrm{pH}$ within the isolated pool during daytime low tides (Maberly 1992, Larsson et al. 1997). A second effect of isolation at low tide is the reduction of water motion to nearly zero relative to the highly turbulent flows associated with wave action. Reduced water motion results in an increase in the thickness of the diffusive boundary layer around receptacles, across which inorganic carbon species $\left(\mathrm{CO}_{2}, \mathrm{HCO}_{3}, \mathrm{CO}_{3}^{-2}\right)$ must diffuse. Given that $\mathrm{CO}_{2}$ diffuses $10^{4}$ times slower in water than in air, and that $\mathrm{HCO}_{3}$ "diffuses even more slowly (Kerby and Raven 1985), a reduction in the bulk flow of medium across an algal thallus has potentially severe consequences and, together with depletion of inorganic carbon by algae in limited volumes of seawater, prob- ably results in photosynthetic carbon limitation in tide pools, with photoinhibition as a likely consequence. This led us to hypothesize that inorganic carbon limitation under calm conditions may provide a signal resulting in gamete release. A prediction of this hypothesis is that increasing the concentration of DIC in calm cultures would alleviate carbon limitation and thus lead to a reduction in gamete release, relative to calm cultures in normal seawater ( $2 \mathrm{mmol} / \mathrm{L}$ dissolved inorganic carbon [DIC]). Earlier, we demonstrated that photosynthetic competence is required for gamete release during calm conditions (Serrão et al. 1996). Here, our field and laboratory studies provide support for a model in which hydrodynamic conditions are sensed chemically via changes in the supply of inorganic carbon across the boundary layer. Fucoids that are emersed at low tide may experience substantially different conditions from tidal pool $F$. distichus, so we also examincd this model in intertidal Fucus vesiculosus L. and Pelvetia compressa (J. Agardh) De Toni (formerly $P$. fastigiata, Silva 1996) to test its generality. Our laboratory studies on these species support the model. This sensitivity to hydrodynamic conditions has important ecological consequences by contributing to the high fertilization efficiencies of fucoid algae (Brawley 1992, Pearson and Brawley 1996, Serrão et al. 1996).

\section{Methods}

\section{Field observations and measurements}

Two moderately exposed sites (A and B) $\sim 50 \mathrm{~m}$ apart, each with four tide pools containing populations of $F$. distichus, were studied at Chamberlain, Maine $\left(44^{\circ} \mathrm{N}, 69^{\circ} 30^{\prime} \mathrm{E}\right)$ in 1996 . The pools at both sites were located slightly above the $F$. spiralis zone on seaward facing slopes with a gentle to moderate grade (see Fig. 1 in Pearson and Brawley 1996). During low tide, water flow in the pools was close to zero, inferred from observations of "egg shadows" that formed directly below receptacles releasing gametes. At high tide the pools never became fully immersed, but were subject to wave-induced water motion from breaking waves and water exchange for periods up to $5 \mathrm{~h}$. Material for laboratory experiments was taken from pools $\sim 20 \mathrm{~m}$ from Site B. Reproduction in $F$. distichus occurs during the winter and early spring, from January through midApril (Pearson and Brawley 1996). Fucoid algae release male and female gametangia (antheridia and oogonia) through multicellular pores to the surface of the alga from spherical, subepidermal conceptacles present throughout the reproductive tissue (receptacles, Fritsch 1945). Eggs are fertilized by motile, biflagellate sperm during, or shortly following, the release of cggs from the oogonia.

Gamete release in $F$. distichus occurs during periods when the tide pools are isolated from water motion, and therefore, gamete relcase can be quantified accurately by measuring the settlement of eggs and zygotes 

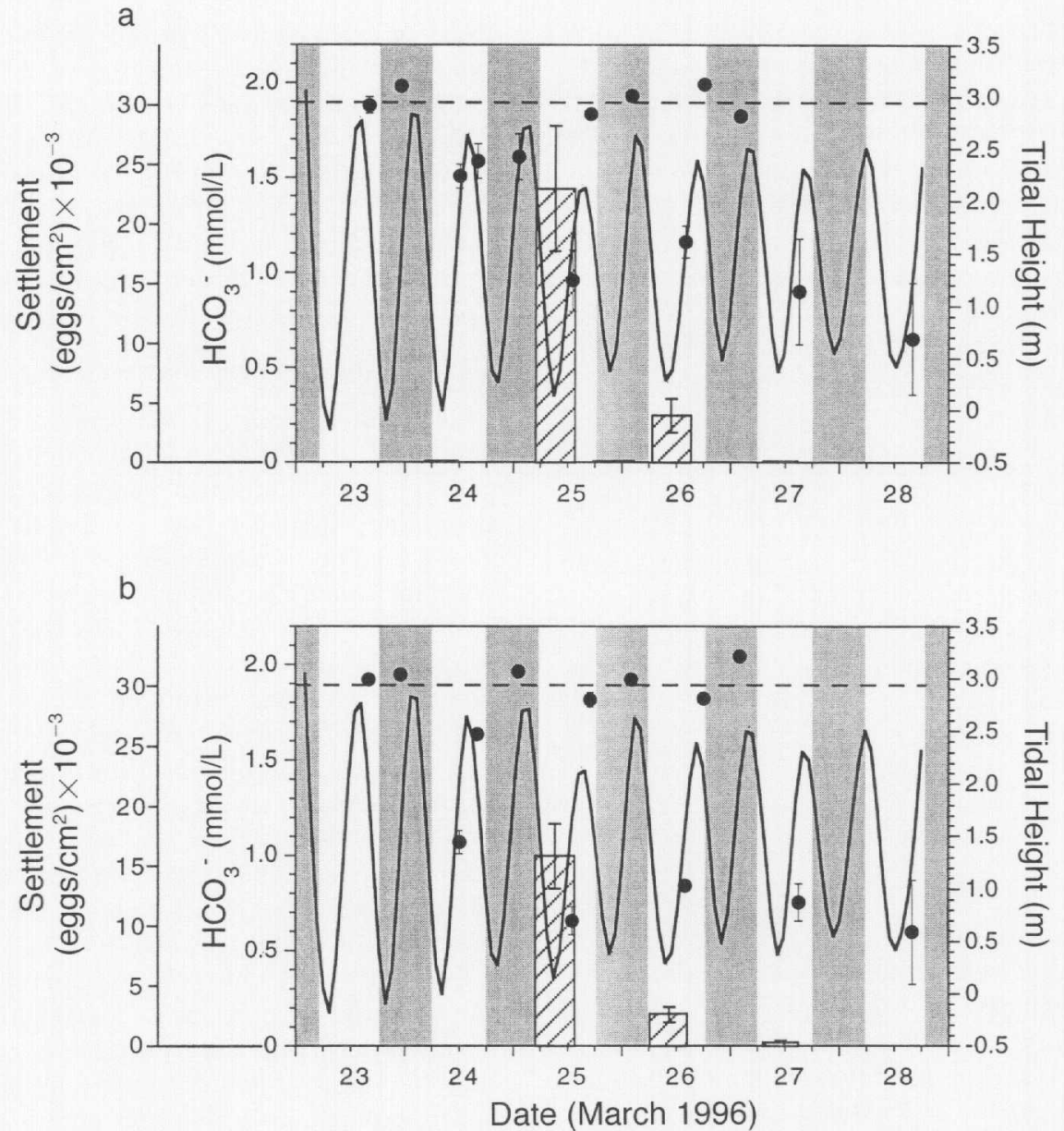

FIG. 1. Gamete release from $F$. distichus (determined from egg settlement [hatched bars] on artificial substrates; $n=6$ $\pm 1 \mathrm{SE}$ ) from tide pools A2 (a) and B4 (b) at Chamberlain, Maine, between 23 and 28 March 1996 (far left axis; the width of the bars illustrates the sampling intervals, separated by high-tide periods when the pools were being washed by waves). The bicarbonate concentration in the pools prior to, or just following, inundation by high tides is shown by filled circles (inner left axis: $n=3 \pm 1 \mathrm{SE}$ ); the mean seawater concentration of bicarbonate is shown by the horizontal dashed line. The phase of the tidal cycle is shown by the solid line (right axis). Darkness (night) is shown by the vertical gray bars.

on artificial substrates. Settlement disks $(28 \mathrm{~mm}$ diameter) were cast from Sea Goin' Poxy Putty (Permalite Plastics, Newport Beach, California) using a silicone rubber mold. The mold was made using Plexiglas disk blanks topped by sandpaper (number 6, from Sweden). Settlement disks fit flush into the lids of plastic film canisters (Pearson and Brawley 1996). These assemblies were placed haphazardly below groups of reproductive algae in the pools ( $n=6$ disks). Disks were placed into two pools (A2 and B4, from sites A and $B$, respectively) following the daytime or nighttime high tide, as soon as the pools stopped being washed by waves, and were collected prior to the following high tide, by carefully placing a film canister over the lid containing the disk under water, and closing it. This method minimized loss of settled eggs and zygotes from the disk surface. Both Pools A2 and B4 were washed during the high tide for $4.5-5 \mathrm{~h}$ on $23 \mathrm{March}$, and continued to be washed for at least $4 \mathrm{~h}$ until 26 March. However, between 27 and 29 March, neither pool received any tidal input (lowest neap tides, 28 March).

We measured fluctuations in inorganic carbon concentration in the pools prior to, during, and immediately following periods of gamete release. At each sampling time (i.e., prior to a high tide), the temperature was recorded, and water samples $(n=3)$ were collected in sealed polypropylene tubes $(15 \mathrm{~mL}$ ) within patches of reproductive individuals in the pools, near the positions of the settlement disks. Seawater controls were collected at Chamberlain during daytime sampling periods for comparison with pool samples. Water samples were stored in darkness at $5^{\circ} \mathrm{C}$ until analysis.

The inorganic carbon concentration in the tide pools during periods of gamete release was determined by the method of Strickland and Parsons (1972). Water 
samples were brought to room temperature $\left(25^{\circ} \mathrm{C}\right)$, the $\mathrm{pH}$ was measured, and major forms of inorganic carbon $\left(\mathrm{CO}_{2}, \mathrm{HCO}_{3}\right.$ and $\left.\mathrm{CO}_{3}{ }^{2}\right)$ were estimated from $\mathrm{pH}$ and alkalinity after titration with a known amount of 0.01 mol/L hydrochloric acid. This method is based on a thermodynamic consideration of the inorganic carbon system (Skirrow 1975). The removal of $\mathrm{CO}_{2}$ during photosynthetic carbon fixation causes an increase in $\mathrm{pH}$ without changing alkalinity; therefore, knowledge of the $\mathrm{pH}$ and alkalinity of a seawater sample is sufficient to calculate the total dissolved inorganic carbon (DIC) present from

$$
[\mathrm{DIC}]=[\mathrm{CA}] \frac{1+K_{2}{ }^{1} / \mathrm{H}^{+}+\mathrm{H}^{+} / K_{\mathrm{LI}}{ }^{1}}{1+2 K_{2}{ }^{1} / \mathrm{H}^{+}}
$$

where [DIC] is the total dissolved inorganic carbon concentration in the water, [CA] is the carbonate alkalinity, and $\mathrm{H}^{+}$is the hydrogen ion activity $\left(=10^{-\mathrm{pH}}\right)$. The first and second apparent dissociation constants (temperature and salinity dependent) for carbonic acid are given by $K_{\mathrm{L} 1}{ }^{2}$ and $K_{2}{ }^{1}$, respectively, and refer to the processes

$$
\begin{aligned}
K_{\mathrm{L}^{2}}{ }^{2}: \mathrm{CO}_{2}+\mathrm{H}_{2} \mathrm{O} & \Leftrightarrow \mathrm{H}^{+}+\mathrm{HCO}_{3}{ }^{-} \\
K_{2}{ }^{1}: \mathrm{HCO}_{3}{ }^{-} & \Leftrightarrow \mathrm{H}^{+}+\mathrm{CO}_{3}^{-2} .
\end{aligned}
$$

In order to determine the quantity of mature gametes available for release, we collected independent samples of mature receptacles ( $n=5$ receptacles per pool; one receptacle from each of five individuals) haphazardly from algae near the settlement disks during each daytime sampling period and fixed them in acetic acid: ethanol (1:3) for analysis. Fixed receptacles were sectioned with a razor blade, rehydrated in distilled water, and observed with an Olympus $\mathrm{BH}-2$ compound microscope at low power. The number of conceptacles, total number of oogonia, and the number of mature oogonia were determined from 10 to 12 sections $(\sim 0.5$ $\mathrm{mm})$ per receptacle. Mature oogonia were defined as those in which cleavage furrows were evident; only oogonia having undergone cell division are released from conceptacles.

\section{Flow measurements in laboratory experiments}

Water velocities in experimental culture vessels were quantified using a pulsed doppler flow meter (Crystal Biotech CBI-8000, model PD-10, Northborough, Massachusetts) with a $2-\mathrm{mm}$ transducer crystal at an angle of $45^{\circ}$ to the direction of flow. Measurements were made with a $31.25 \mathrm{KHz}$ pulse repetition frequency, 5 $\mathrm{mm}$ from the sensor, and $3-4 \mathrm{~mm}$ from the wall of the flask or culture dish. Ground black pepper was added to the seawater during flow velocity measurements to provide particles for the reflection of the signal. The output was recorded at $25 \mathrm{~mm} / \mathrm{s}$ on a Gould $220 \mathrm{high}$ speed chart recorder (Rutherford, New Jersey, USA). Flow was generated in two ways: either using an orbital shaker (Lab-Line Instruments Melrose Park, Illinois,
USA) or by magnetic stirring plates. On the orbital shaker, flow rates were measured in $125-\mathrm{mL}$ flasks containing $30 \mathrm{~mL}$ seawater at $150 \mathrm{rpm}$ (for experiments with $F$. distichus) and in $250-\mathrm{mL}$ flasks containing 50 $\mathrm{mL}$ seawater at $120 \mathrm{rpm}$ (for experiments with $F$. vesiculosus). Magnetic stirring was used to generate flow in culture dishes containing $200 \mathrm{~mL}$ seawater in an experiment with $F$. distichus, or in 1 - $\mathrm{L}$ flasks filled to capacity in an experiment with $P$. compressa.

\section{Laboratory experiments: Fucus distichus}

Water motion and light regime.-We investigated the effects of different hydrodynamic regimes on gamete release by culturing receptacles under calm, agitated, and simulated tidal conditions. The effect of photoperiod on gamete release was tested by culturing receptacles under a natural photoperiod, or in constant light. Intact individuals of $F$. distichus were collected for experiments during darkness at 0400 EST, 24 March, to minimize disruption of any endogenous or environmentally cued responses to the natural light field. Algae were obtained from a pool $-20 \mathrm{~m}$ from Site A, placed into a bucket of seawater, and transported back to the laboratory in darkness. Immediately after returning, groups of 3-4 receptacles were assigned randomly to replicate $125-\mathrm{mL}$ flasks containing $30 \mathrm{~mL}$ of filtered $(1-\mu \mathrm{m}$ mesh) seawater $(n=5)$. The temperature of the walk-in culture room was maintained at $10^{\circ} \pm$ $1^{\circ} \mathrm{C}$; the range of temperature maxima recorded for the tide pools during the experimental period was $5^{\circ}-13^{\circ} \mathrm{C}$, and the range of temperature minima (recorded at night) was $-3^{\circ}-0^{\circ} \mathrm{C}$. Constant photosynthetic photon flux density (PPFD) was provided with metal halide lights at $500 \mu \mathrm{mol}$ photons $\cdot \mathrm{m}^{-2} \cdot \mathrm{s}^{-1}$; for those treatments requiring a natural photoperiod ( 12 h light : 12 h dark), flasks were wrapped in aluminum foil between 1800 and 0600 EST. Water motion was provided by an orbital shaker at $150 \mathrm{rpm}$.

In natural populations, tidal input provides fresh seawater $\sim 2$ h prior to each high tide, except during some neap tides, when the pools remain isolated. Thus, six of the eight experimental treatments were sampled $2 \mathrm{~h}$ prior to the times of high tide in the field. The medium was changed at this time, and the number of released eggs was determined using a dissecting microscope. Results were analyzed using a repeated-measures ANOVA with gamete release as the response variable, two repeated factors ("day" three levels, and "photoperiod phase": two levels), plus six levels of the factor "treatment" as follows: (1) three levels of water motion: constant agitation, constant calm, and a simulated tidal regime in which agitation was provided for $2 \mathrm{~h}$ prior to and $2 \mathrm{~h}$ following high tide, and (2) two light regimes, $12 \mathrm{~h}$ light : $12 \mathrm{~h}$ dark and $24 \mathrm{~h}$ (constant) light. The tidal sampling regime of 12.5 -h periods contained both light and darkness. Therefore, to clarify the effects of PPFD, two more calm treatments were analyzed in a second experiment, carricd out during the 
same period. These were sampled every $12 \mathrm{~h}$ at the beginning and end of the light period. One of these was kept in constant light and the other in a $12 \mathrm{~h}$ light : $12 \mathrm{~h}$ dark photoperiod. In this and all further experiments homogeneity of variance assumptions were verified with Cochran's test. Differences between means were detected with Tukey's tests, using the appropriate mean square.

Effects of dissolved inorganic carbon supply.-We investigated the role of DIC in gamete release under calm conditions in $F$. distichus using the same photoperiod, PPFD, and temperature described above. Gamete release was sampled every $12 \mathrm{~h}$, at the beginning and end of the light periods. Receptacles ( $3-4$ per replicate: $n=5$ ) were placed in 125 -mL flasks containing $30 \mathrm{~mL}$ of unbuffered seawater containing either 2 $\mathrm{mmol} / \mathrm{L}$ (natural seawater) or $20 \mathrm{mmol} / \mathrm{L}$ DIC (supplemented with $18 \mathrm{mmol} / \mathrm{L} \mathrm{NaHCO}_{3}$ ). Data were analyzed by repeated-measures ANOVA, after confirming homogeneity of variance assumptions with Cochran's test.

Effects of water motion vs. receptacle motion.-We investigated whether the inhibitory effect of agitation on gamete release required movement of receptacles in the water column using culture dishes $(n=4)$ containing $200 \mathrm{~mL}$ natural seawater in a walk-in culture chamber at $12^{\circ} \pm 1{ }^{\circ} \mathrm{C}$, with a $12 \mathrm{~h}$ light: $12 \mathrm{~h}$ dark photoperiod, and a PPFD of 250-300 $\mu \mathrm{mol}$ photons $\cdot \mathrm{m}^{2} \cdot \mathrm{s}^{-1}$. Water motion was provided with stir bars and magnetic stir plates. Receptacles (two per replicate) were kept parallel and immobilized with respect to the water flow by holding them between two thin plastic strips supported $\sim 2 \mathrm{~cm}$ from the floor of the culture vessel. The four treatments (presence or absence of water motion; with or without immobilization of receptacles) were analyzed by repeated-measures ANOVA. No attempt was made to control for physical contact between nonimmobilized receptacles or between receptacles and the walls of the culture vessels; such contact did not produce abrasion

\section{Laboratory experiments: Pelvetia compressa and} Fucus vesiculosus

Pelvetia compressa is a monoecious fucoid inhabiting the intertidal zone of Pacific North America. As an experimental organism for studies of hydrodynamic effects on gamete release, $P$. compressa is advantageous because it sheds very few gametes in the light during a $\geq 4-h$ induction period, but relcases massive numbers within 2-5 min of a transfer from light to darkness (Jaffe 1954); 6-h illumination was used in the experiments reported in the present communication. Pelvetia compressa was collected from either Monterey, or Pigeon Point, California; receptacles in sealed plastic bags, or whole algae stored between layers of damp paper, were shipped overnight on ice packs in styrofoam coolers. Material was stored in darkness at $5^{\circ} \mathrm{C}$ and normally used in experiments within $3-4 \mathrm{~d}$, and always within $10 \mathrm{~d}$, of collection. Before use, receptacles were pretreated to minimize potential artifacts associated with storage, by placing them in natural seawater in the light $\left(150 \mu \mathrm{mol}\right.$ photons $\left.\cdot \mathrm{m}^{2} \cdot \mathrm{s}^{-1}\right)$, for $6 \mathrm{~h}$ with vigorous water motion (agitation at $150 \mathrm{rpm}$ in $2-\mathrm{L}$ flasks).

$\left[\mathrm{HCO}_{3}^{-}\right],\left[\mathrm{CO}_{2}\right] \mathrm{pH}$. We further investigated the effect of the inorganic carbon dioxide system, in particular bicarbonate $\left(\mathrm{HCO}_{3}{ }^{-}\right)$, and dissolved $\mathrm{CO}_{2}$, on gamete release in $P$. compressa, by varying their relative concentrations in seawater over the $\mathrm{pH}$ range 7.1 8.6. For example, at equilibrium in seawater containing $2 \mathrm{mmol} / \mathrm{L} \mathrm{HCO}_{3}{ }^{-}$at $\mathrm{pH} 7.1$, there is $182.4 \mu \mathrm{mol} / \mathrm{L}$ $\mathrm{CO}_{2}$; at $\mathrm{pH} 8.0,23 \mu \mathrm{mol} / \mathrm{L}$, whereas at $\mathrm{pH} 8.6$, the concentration of $\mathrm{CO}_{2}$ is only $5.8 \mu \mathrm{mol} / \mathrm{L}$ (calculated from data in Skirrow [1975]). To produce seawaters with DIC concentrations lower than that of normal seawater, we first made DIC-free seawater, before adding back a known quantity of $\mathrm{NaHCO}_{3}$. Natural filtered seawater was acidified to $\mathrm{pH} 3$ and bubbled overnight (minimum of $12 \mathrm{~h}$ ) with air passed through $1 \mathrm{~mol} / \mathrm{L}$ $\mathrm{NaOH}$ to remove $\mathrm{CO}_{2}$ (Forster and Dring 1992). The seawater containers were 4-L polypropylene screw-top jars with holes drilled in the lids for air lines to enter during bubbling. After $12 \mathrm{~h}, 10 \mathrm{mmol} / \mathrm{L}$ Tris base was added, and the $\mathrm{pH}$ was adjusted with $10 \mathrm{~mol} / \mathrm{L} \mathrm{HCl}$. Positive pressure was maintained throughout by passing $\mathrm{CO}_{2}$-free air through the seawater, preventing contamination with atmospheric $\mathrm{CO}$. The jar was then sealed and the seawater used in experiments the same day.

Water motion vs. [DIC].-If the major effect of water motion on gamete release is to increase the rate of DIC supply to the algal thallus, then we reasoned that gamete release should be independent of water motion in the absence of DIC. This hypothesis was tested in a closed system, in which exchange between the seawater medium and the air was prevented. Flasks $(1 \mathrm{~L})$ containing $\mathrm{NaHCO}_{3}$ to give final concentrations of DIC of 0,2 and $10 \mathrm{mmol} / \mathrm{L}$, were flushed with $\mathrm{CO}_{2}$-free air for several minutes, completely filled with DIC-free seawater, and sealed with a rubber stopper (number 10 , $\sim 3 \mathrm{~cm}$ thick). Magnetic stir bars were added to flasks recciving water motion, which was provided by stirring plates. The experiment was a $2 \times 3$ factorial design with two lcvels of water motion (present or absent), and three levels of [DIC] $(0,2$, and $10 \mathrm{mmol} / \mathrm{L})$. At the start of the light incubation period, receptacles ( 10 in each of the six flasks) were quickly added to the flasks, which were then rescaled. After $6 \mathrm{~h}$ in the light (250 $\mu \mathrm{mol}$ photons $\cdot \mathrm{m}^{2} \cdot \mathrm{s}^{-1}$ ) at $15^{\circ} \mathrm{C}$, the receptacles from each flask were removed, and two per replicate $(n=5)$ placed in darkness in $60-\mathrm{mm}$ petri dishes in $15 \mathrm{~mL}$ natural seawater. Gamete release was quantified after $30 \mathrm{~min}$.

Fucus vesiculosus is a dioecious fucoid that inhabits the mid-intertidal zone of moderately exposed shores throughout most of its distribution on the American 
TABLE 1. Temperature, $\mathrm{pH}$ and $\mathrm{HCO}_{3}{ }^{-}$concentration in tide pools $\mathrm{A} 2$ and $\mathrm{B} 4$ before and after high tides during gamete release from $F$. distichus between 24 and 27 March 1996.

\begin{tabular}{ccccc}
\hline \hline Date/Time & Sampling time & $\begin{array}{c}\text { Temperature } \\
\left({ }^{\circ} \mathrm{C}\right)\end{array}$ & $\begin{array}{c}\mathrm{HCO}_{3}^{-} \\
\left(\mathrm{mmol}^{-} \mathrm{L}\right)\end{array}$ & $\mathrm{pH}$ \\
\hline Pool A2 & & & & \\
24 Mar 1996/1230 & [-] DHT & 8 & $1.51(0.06)$ & $8.99(0.07)$ \\
24 Mar 1996/1600 & [+] DHT & 7 & $1.59(0.09)$ & $8.98(0.09)$ \\
25 Mar 1996/0030 & [-] NHT & 1 & $1.61(0.12)$ & $8.64(0.02)$ \\
25 Mar 1996/1330 & [-] DHT & 10 & $0.96(0.16)$ & $8.87(0.07)$ \\
25 Mar 1996/1700 & [+] DHT & 4 & $1.83(0.03)$ & $8.23(0.02)$ \\
26 Mar 1996/0130 & [-] NHT & 1 & $1.93(0.01)$ & $7.79(0.01)$ \\
26 Mar 1996/1400 & [-] DHT & 13 & $1.16(0.08)$ & $9.13(0.05)$ \\
26 Mar 1996/1830 & [+] DHT & 2 & $1.99(0.01)$ & $7.79(0.03)$ \\
27 Mar 1996/0200 & [-] NHT & -1 & $1.82(0.03)$ & $7.30(0.02)$ \\
27 Mar 1996/1500 & [-] DHT & 11 & $0.90(0.28)$ & $8.96(0.06)$ \\
Pool B4 & & & & \\
24 Mar 1996/1230 & [-] DHT & 10 & $1.07(0.06)$ & $8.98(0.04)$ \\
24 Mar 1996/1600 & [+] DHT & 7 & $1.63(0.02)$ & $8.60(0.01)$ \\
25 Mar 1996/0030 & [-] NHT & 0 & $1.96(0.01)$ & $8.58(0.01)$ \\
25 Mar 1996/1330 & [-] DHT & 10 & $0.66(0.08)$ & $8.93(0.03)$ \\
25 Mar 1996/1700 & [+] DHT & 3 & $1.82(0.04)$ & $8.19(0.01)$ \\
26 Mar 1996/0130 & [-] NHT & 1 & $1.92(0.01)$ & $7.63(0.01)$ \\
26 Mar 1996/1400 & [-] DHT & 13 & $0.84(0.02)$ & $9.21(0.04)$ \\
26 Mar 1996/1830 & [+] DHT & 2 & $1.82(0.01)$ & $7.76(0.02)$ \\
27 Mar 1996/0200 & [-] NHT & -1 & $2.05(0.01)$ & $7.30(0.02)$ \\
27 Mar 1996/1500 & [-] DHT & 12 & $0.76(0.10)$ & $8.98(0.02)$ \\
\hline
\end{tabular}

Notes: Values of $\mathrm{pH}$ and $\mathrm{HCO}_{3}^{-}$are means and $1 \mathrm{SE}$ (in parentheses), $n=3$. The timing of sampling in relation to immersion of pools by the high tide is shown $([-]=$ before immersion, $[+]=$ after immersion). DHT $=$ daytime high tide and $\mathrm{NHT}=$ nighttime high tide. The seawater temperature during the sampling period was $3^{\circ} \pm 0.5^{\circ} \mathrm{C},\left[\mathrm{HCO}_{3}{ }^{-}\right]$was $1.85 \pm 0.02 \mathrm{mmol} / \mathrm{L}$ $(n=12)$, and the $\mathrm{pH}$ was $8.02 \pm 0.04(n=12)$.

and European coasts of the north Atlantic. The receptacles were collected from females at Chamberlain, Maine, USA, and used in experiments immediately. The effects of DIC concentration on gamete release by F. Vesiculosus were studied by culturing $\left(17^{\circ} \mathrm{C}, 250\right.$ $\mu \mathrm{mol}$ photons $\mathrm{m}^{2} \cdot \mathrm{s}^{-1}$ ) receptacles under calm or agitated ( $120 \mathrm{rpm}$ ) conditions in $250-\mathrm{mL}$ glass flasks (five receptacles per flask) with $50 \mathrm{~mL}$ of scawater containing $0 \mathrm{mmol} / \mathrm{L}, 2 \mathrm{mmol} / \mathrm{L}$ or $20 \mathrm{mmol} / \mathrm{L}$ of DIC. Exchange of $\mathrm{CO}_{2}$ between the air and seawater was not entirely prevented in this experiment, therefore " 0 mmol/L" DIC, in reality, represents a low concentration. but one greater than zero: flasks were purged with $\mathrm{CO}$--tree air prior to the experiment, but did not remain completely air-tight throughout the incubation period. The seawater was prepared as described above for $P$. compressa, except that the $\mathrm{pH}$ was readjusted to $\mathrm{pH}$ 8.0 with $\mathrm{HCl}$ and $\mathrm{NaOH}$ instead of being buffered with Tris. Receptacles cultured in natural seawater under agitated or calm conditions were used as controls. The receptacles were exposed to the treatments for $8 \mathrm{~h}$, after which the numbers of eggs released were counted under a dissecting microscope.

\section{RESUITS}

The settlement of eggs and zygotes of $F$. distichus in tide pools occurs with the onset of the daytime low tide series and occurs during low tide when pools are isolated from wave action (Pearson and Brawley 1996). Gamete release occurred on the same tides in different pools, with most gametes being released on a single day, although there was a further, small release on the day following the major event (Fig. 1). During the 2d period of gamete release, almost no release occurred during the nighttime low tide periods, resulting in a marked diurnal pattern of gamete release and settlement. Gamete release was associated with large fluctuations in the bicarbonate concentration and $\mathrm{pH}$ in the tide pools (Fig. 1, Table 1). On 24 March, one day prior to gamete release, there was $\sim 1.5 \mathrm{mmol} / \mathrm{L}$ bicarbonate, both before and after the daytime high tide had flushed Pool A2, and prior to the high tide on the night of the 24-25 March (Fig. 1a). This was slightly lower than the average seawater concentration, which was $1.85 \pm$ $0.02 \mathrm{mmol} / \mathrm{L}$ during the study period. Following the daytime low tide period on 25 March, during which gametes were released, the bicarbonate concentration had fallen to $0.96 \mathrm{mmol} / \mathrm{L}$. Over the next scveral days, there was a pattern of $\mathrm{pH}$ increases and bicarbonate decreases during low tide in the light, followed by a return to nearly the concentration of bicarbonate in bulk seawater after flushing of the pools at high tide (or in darkness at night). A similar pattern occurred in Pool B4 at a site some $50 \mathrm{~m}$ from Site $\mathrm{A}$, although a decline in bicarbonate to $\sim 1 \mathrm{mmol} / \mathrm{L}$ occurred on the $24 \mathrm{March}$, one day prior to gamete release (Fig. 1b, Table 1). The inorganic carbon status of the pools was not extensively sampled on 27 and 28 March, following the peak of gamete release, because they were no longer washed at high tide. Low concentrations of bicarbonate were 
FIG. 2. Total number of oogonia (solid symbols; left-hand axis) and number of mature oogonia (open symbols; right-hand axis) per conceptacle of $F$. distichus, determined by sectioning mature receptacles collected from pools $\mathrm{A} 2$ and B4, between 23 and 28 March $1996(n=$ 5 receptacles $\pm 1 \mathrm{SE}$ ).

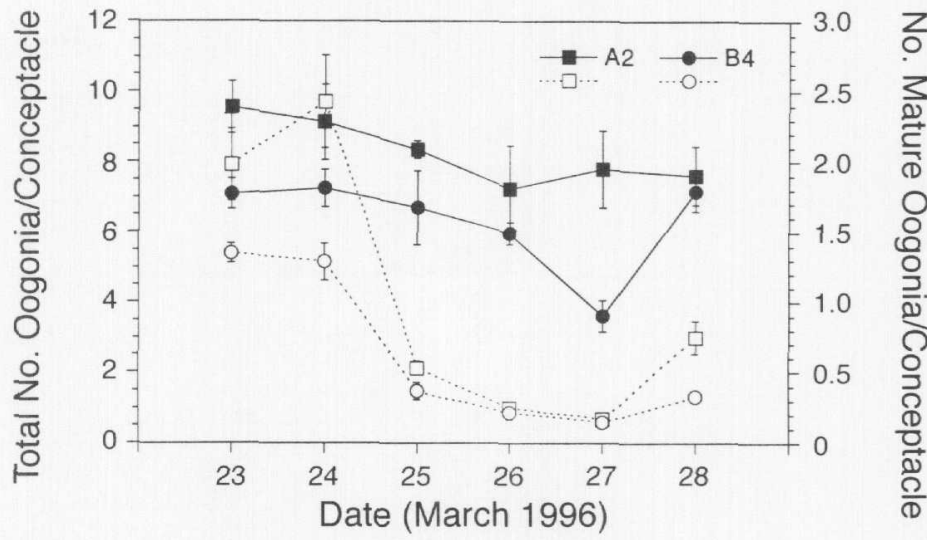

measured on these two days following the daytime low tide period, however, there was a negligible amount of gamete release. The reason for this appears to be exhaustion of the supply of mature oogonia (Fig. 2, right axis). Mature oogonia are cleaved into eight eggs that remain tightly packed inside the oogonium. The total numbers of oogonia did not decline significantly between 23-24 March (prior to release) and 25-26 March (when relcase occurred), although there were fewer in samples taken on 27 March (Fig. 2, left axis: ANOVA, $F_{5,4}=3.18 ; P<0.02$ ). However, numbers of mature oogonia decreased precipitously between 24 and 25 March, and reached a minimum on 27 March for receptacles from Pools A2 and B4 (ANOVA, date and pool interaction; $F_{5,48}=5.04 ; P<0.001$; Tukey's multiple comparison tests). It is of interest that numbers of mature oogonia began to increase by the 28 March, although gamete release occurs only at $\sim 2$ wk intervals (i.e., during the daytime low tide series; Pearson and Brawley 1996).

The patterns of release of gametes from natural populations of $F$. distichus suggest that several endogenous and environmental cues might be involved in the timing of gamete release, so these were manipulated in lab- oratory cultures. The velocity, range, and periodicity of the flow within the experimental vessels for this experiment are shown in Fig. 3a. The mean velocity was $0.35 \mathrm{~m} / \mathrm{s}$, but oscillated over the range -0.04 to $0.61 \mathrm{~m} / \mathrm{s}$. As in the 1995 field season (shown in Serrão et al. 1996), gametc release in culture coincided with days when it was observed in field populations in 1996 (cf. Figs. 1 and 4), and similar patterns of gamete release were observed under either calm or simulated tidal conditions (Fig. 4a, b). Many fewer gametes were released in the afternoon/evening periods than in the mornings (particularly under simulated tidal conditions). Cultures in which gamete release was quantified during light vs. dark periods (Fig. 4c) indicated that few gametes were released during darkness. Constant agitation of cultures (i.e., permanent "high tide" conditions) effectively blocked gamete release throughout the sampling period (Fig. 4d). Thus, although tidal conditions are not necessary for patterns of gamete release similar to those observed in the field, periods of low water motion are required (see also Serrão et al. 1996). When previously agitated receptacles were returned to calm conditions in the light at the end of the experimental period, massive gamete release was stimulated
FIG. 3. Chart traces showing flow characteristics in culture vessels used for the experiments (March 1996) reported in this paper. Flow velocity was determined using a pulsed doppler flowmeter as described in the text. Trace a: 125 $\mathrm{mL}$ flask containing $30 \mathrm{~mL}$ seawater, orbital shaker at $150 \mathrm{rpm}$. Trace b: $250-\mathrm{mL}$ flask containing $50 \mathrm{~mL}$ seawater, orbital shaker at 120 rpm. Trace c: $200 \mathrm{~mL}$ seawater in $250-\mathrm{mL}$ culture dish, magnetic stir plate. Trace d: 1 - L flask completely full of seawater and sealed with rubber stopper, magnetic stir plate. Traces taken with Gould 220 chart recorder at $25 \mathrm{~mm} / \mathrm{s}$.

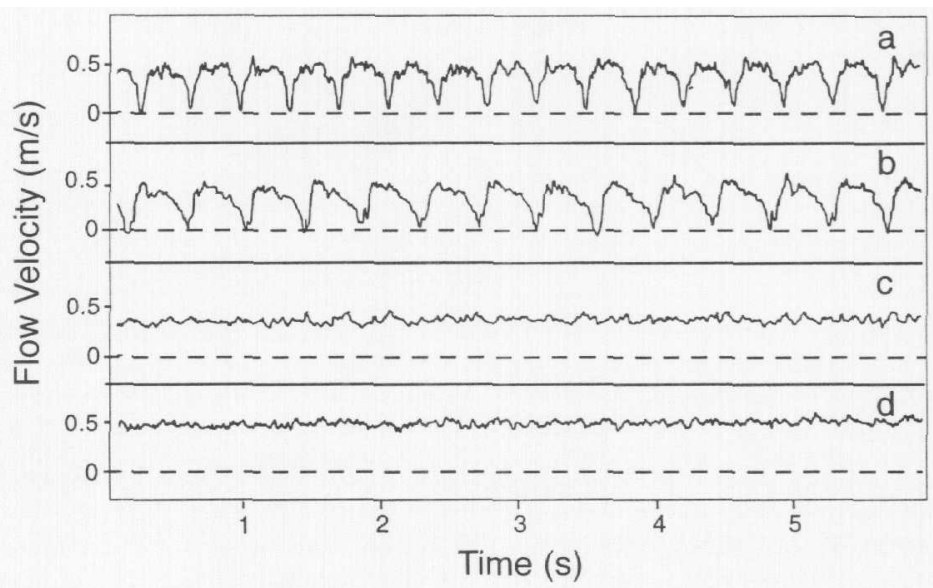



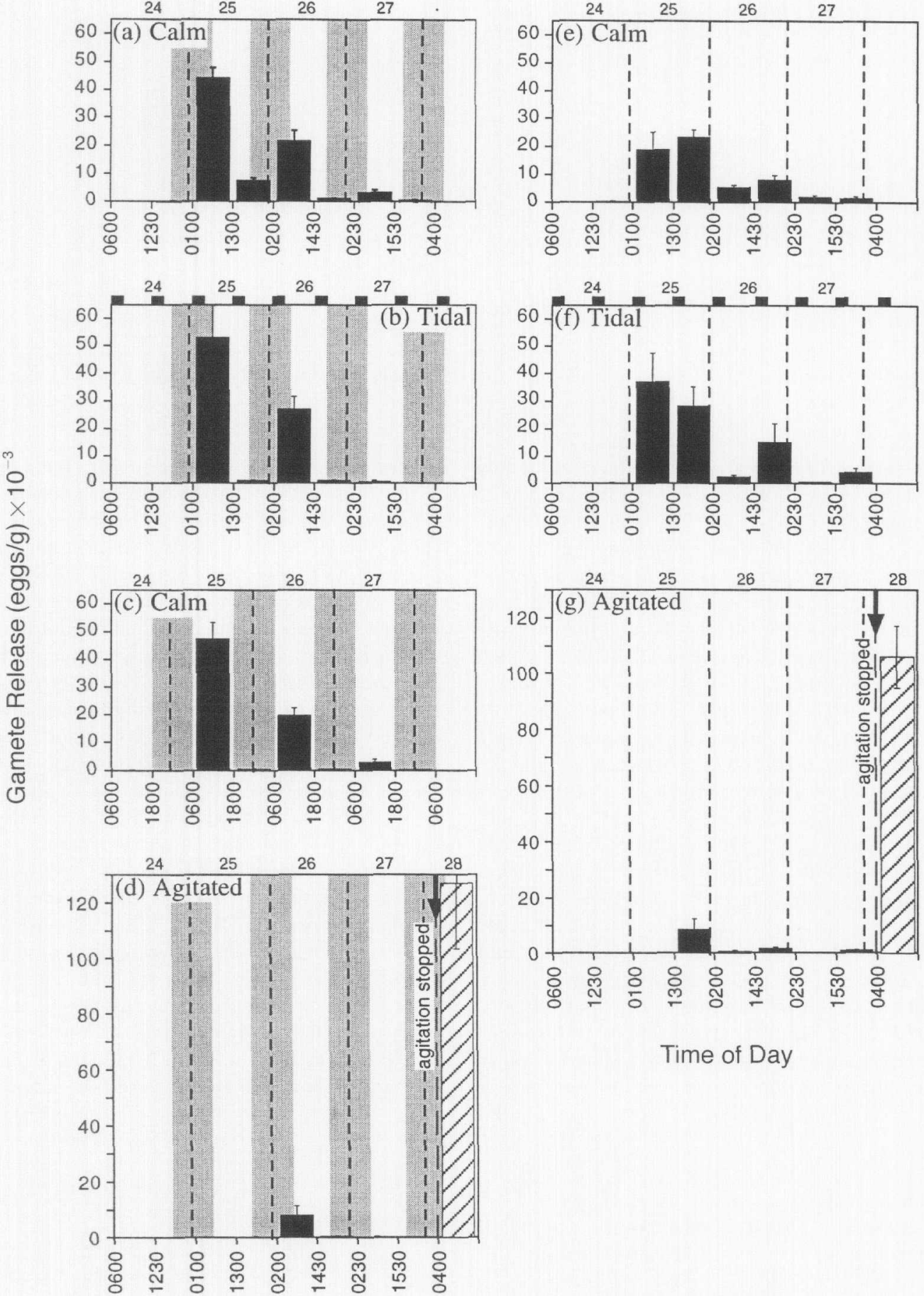

Time of Day

Time of Day

FIG. 4. Gamete release from cultured receptacles of $F$. distichus in laboratory experiments between 24 and 28 March 1996. Units for gamete release are per gram fresh mass of receptacle throughout figures. Gray bars in (a)-(d) are dark portions of the photoperiod, and the dashed lines in all graphs are placed to show actual midnight. All values are means \pm 1 SE ( $n$ $=5$ flasks per treatment; repeated measures on the same receptacles). The treatments are: (a) $12: 12 \mathrm{~h}$ photoperiod; constant calm conditions. (b) $12: 12 \mathrm{~h}$ photoperiod; receptacles agitated on an orbital shaker $(150 \mathrm{rpm})$ during periods when tide pools were inundated by waves in the field, to simulate tidal conditions. Black bars above the graph show the periods of agitation. (c) 12:12 h photoperiod; constantly calm conditions. (d) $12: 12 \mathrm{~h}$ photoperiod; constant water motion provided by agitation on an orbital shaker $(150 \mathrm{rpm})$ until 28 March (black bars), followed by calm conditions (vertical arrow) during the sampling interval 0400-1630 h (stippled bars). Conditions in (e) are as in (a), (f) as (b), and (g) as (d) except for constant light in (g). Gamete release in treatments (a), (b), (d), (e), (f), and (g) was determined for periods corresponding to the onset of "high tide" until immediately prior to the following "high tide." Gamete release in treatment (c) was quantified during light vs. dark intervals. See Methods for further details. 
TABLE 2. Cumulative gamete release by receptacles of $F u$ cus distichus in culture between 24-27 March (calm and tidal conditions) and 24-28 March (agitated cultures returned to calm conditions on 28 March: see Fig. 4 and Methods for details).

\begin{tabular}{ccc}
\hline $\begin{array}{c}\text { Water motion } \\
\text { regime }\end{array}$ & $\begin{array}{c}\text { Photoperiod } \\
\text { regime } \\
\text { (light: dark h) }\end{array}$ & $\begin{array}{c}\text { Cumulative gamete release } \\
(\text { no. eggs/g) } \\
\pm 1 \mathrm{SE}\end{array}$ \\
\hline Calm & $24: 0$ & $60032^{\mathrm{a}} \pm 5570$ \\
Calm & $12: 12$ & $79262^{\mathrm{a}} \pm 8944$ \\
Tidal & $24: 0$ & $88029^{\mathrm{a}} \pm 7623$ \\
Tidal & $12: 12$ & $83175^{\mathrm{a}} \pm 12198$ \\
Agitated & $24: 0$ & $118093^{\mathrm{a}} \pm 9221$ \\
Agitated & $12: 12$ & $136366^{\mathrm{b}} \pm 5790$ \\
\hline
\end{tabular}

Notes: Values are means $\pm 1 \mathrm{SE}(n=5)$. A one-way ANO$\mathrm{VA}$ was performed on the data, and values with the same letter do not differ significantly $(P>0.05$, Tukey's multiple comparison tests)

† Units of gamete release are per gram fresh mass of receptacle.

(Fig. 4d, g), which exceeded the cumulative release from tidal and calm treatments (Table 2).

The possibility that an endogenous rhythm underlies the diurnal periodicity of gamete release in both calm and simulated tidal cultures was investigated under constant light. The onset and duration of release also coincided with that in the field under these conditions (cf. Fig. 1 and Fig. 4e, f), which indicates that an endogenous rhythm of gamete development and/or release with a circatidal (or semilunar) periodicity may occur in $F$. distichus. However, the light: dark oscillations in the quantity of gametes released disappeared in constant light, which suggests that an endogenous circadian rhythm of gamete release was absent. Very little gamete release was again found in constantly agitated cultures (Fig. $4 \mathrm{~g}$ ). The results of our culture experiments demonstrate that calm conditions (low water motion) and a light: dark cycle were necessary and sufficient to generate patterns of gamete release similar to those observed in the field, at least in short-term culture. Gamete release during the afternoon/cvening period in tidal cultures appears to be lower than in calm cultures. This is likely to be because the 4 -h period of agitation given to tidal cultures occurred during the afternoon light period, and thus gamete release was prevented by water motion.

Receptacles of $F$. distichus cultured in seawater containing $20 \mathrm{mmol} / \mathrm{L}$ DIC released significantly fewer gametes compared to receptacles cultured in seawater with natural levels of DIC (Fig. 5; repeated-measures ANOVA; $\left.F_{2.20}=10.38, P<0.001\right)$. There were no significant differences in the numbers of gametes released by the two treatments before and after the release period, which occurred over $2 \mathrm{~d}$, or during dark periods.

The effects of inorganic carbon concentration on gamete release were investigated in more detail using Pelvetia compressa as an experimental organism. By altering the scawater $\mathrm{pH}$, we manipulated the relative amounts of inorganic carbon species present in the me-

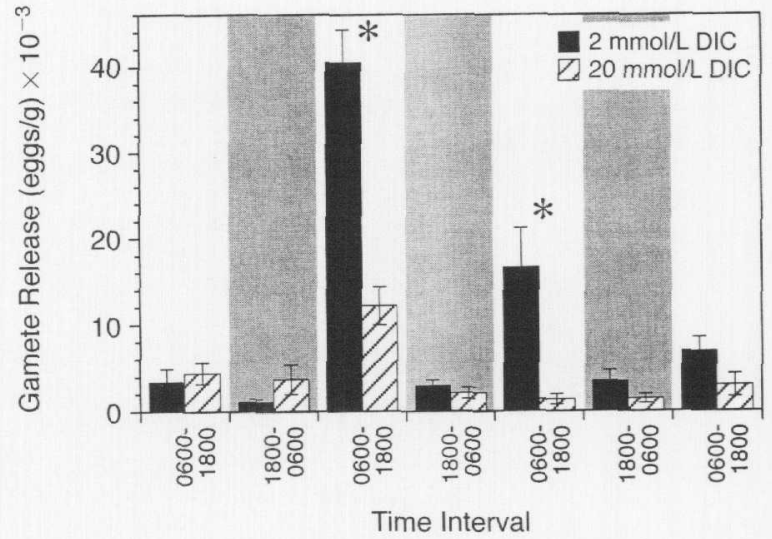

FIG. 5. The effect of DIC (dissolved inorganic carbon) on gamete release by receptacles of $F$. distichus under calm conditions. Gray bars show the dark part of the photoperiod $(12: 12 \mathrm{~h})$. Inhibition of gamete release in the presence of 20 $\mathrm{mmol} / \mathrm{L}$ DIC in the light is shown by asterisks (repeatedmeasures ANOVA; $P<0.001)$. Values are means $\pm 1 \mathrm{sE}(n$ $=5)$. Cultures were maintained in unbuffered, filtered $(1-\mu \mathrm{m}$ mesh) seawater, with or without addition of $\mathrm{NaHCO}_{3}$. Units for gamete release are per gram fresh mass of receptacle.

dium, allowing their effects on gamete release to be investigated. Gamete release declined under calm culture conditions as bicarbonate concentration was increased over the range $0.5-20 \mathrm{mmol} / \mathrm{L}$ (Fig. 6a). An interaction between the effects of $\mathrm{pH}$ and bicarbonate concentration resulted from a higher gamete release in $10 \mathrm{mmol} / \mathrm{L}$ bicarbonate at $\mathrm{pH} 7.1$ compared to $\mathrm{pH} 8.6$ (ANOVA; $F_{8.60}=2.62, P=0.016$ ). Although gamete release also declined with increasing concentrations of $\mathrm{CO}_{2}$ at each $\mathrm{pH}$ tested, the slopes of the curves varied between $\mathrm{pH}$ treatments to a much greater extent than when the data are expressed relative to $\left[\mathrm{HCO}_{3}\right]$ (cf. Fig. 6a and b). Thus, at $20 \mathrm{mmol}^{\mathrm{L}} \mathrm{HCO}_{3}^{-}$gamete release was low and not significantly different between pH 7.1 and 8.6 (Fig. 6a), representing a range of $\mathrm{CO}_{2}$ between $57.7 \mu \mathrm{mol} / \mathrm{L}(\mathrm{pH} 8.6)$ and $1824 \mu \mathrm{mol} / \mathrm{L}(\mathrm{pH}$ 7.1). Similarly, the decline in gamete release with increasing concentration of $\mathrm{CO}_{3}^{-2}$ was not consistent over the (relatively narrow) $\mathrm{pH}$ range tested (data not shown). The inhibition of gamete release by inorganic carbon thereforc correlates most closely with changes in the concentration of $\mathrm{HCO}_{3}$

Gamete release from receptacles of $F$. vesiculosus was inhibited by water motion, and declined significantly with an increasing concentration of DIC (Fig. 7; ANOVA, no interaction between water motion and DIC: $F_{3.24}(\mathrm{DIC})=8.58, P<0.0001 ; F_{1.24}$ (water motion) $=16.70, P<0.0001$ ). The mean flow velocity in the conditions used in this experiment was $0.30 \mathrm{~m} /$ $\mathrm{s}$, ranging between -0.09 and $0.58 \mathrm{~m} / \mathrm{s}$ (Fig. 3b). Greater gamete release occurred in seawater with " 0 mmol/ L"' DIC than either normal $(2 \mathrm{mmol} / \mathrm{L})$ or high $(20$ mmol/L) DIC seawater (Tukey's multiple comparison tests). The lack of an interaction between [DIC] and 

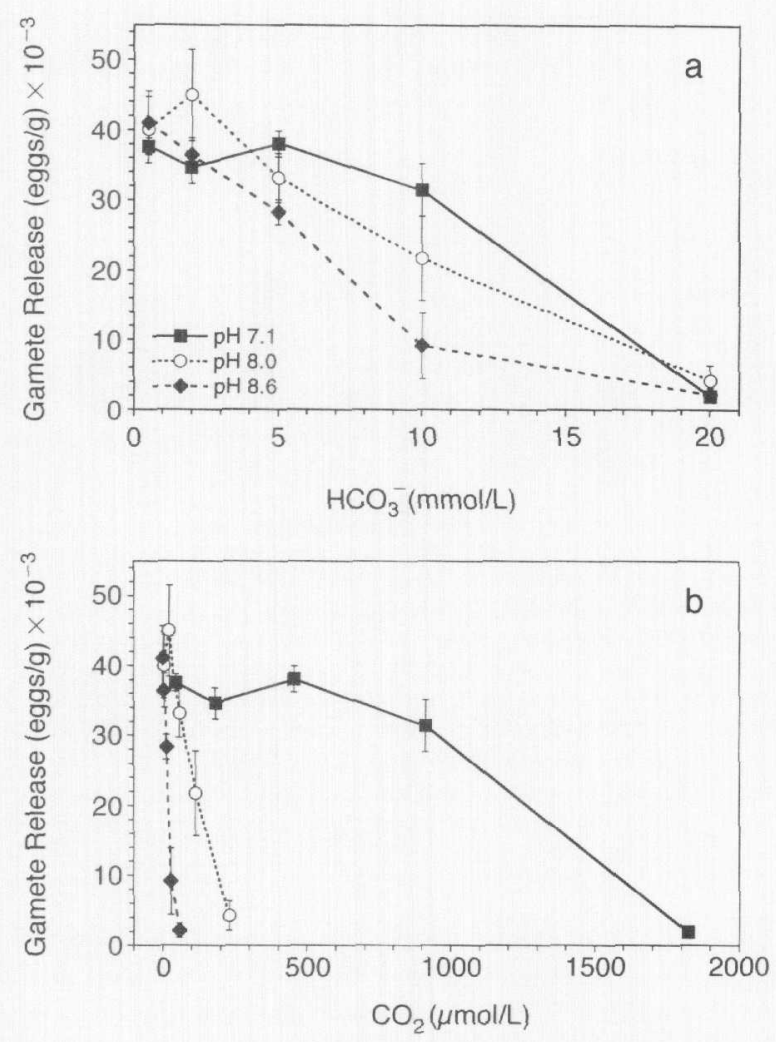

FIG. 6. The effects of DIC and seawater $\mathrm{pH}$ on gamete release by receptacles of $P$. compressa under calm conditions, in response to (a) bicarbonate concentration, and (b) dissolved carbon dioxide concentration. Receptacles were incubated in DICfree seawater, buffered with $10 \mathrm{mmol} / \mathrm{L}$ Tris, and with $\mathrm{NaHCO}_{3}$ added to the required level. Values are means $\pm 1 \mathrm{SE}(n=5)$.

water motion may have arisen because exchangc of air with " 0 mmol/L" treatments was not completely prevented.

In an experiment designed to separate the effects of

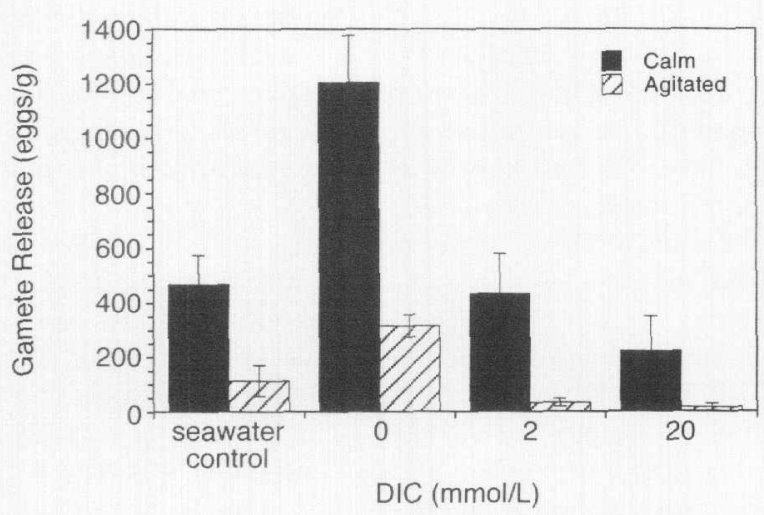

FIG. 7. The effect of DIC and water motion on gamete release by receptacles of $F$. vesiculosus. Values are means \pm $1 \mathrm{SE}(n=4)$. The experiment was done in unbuffered, DICfree seawater with or without addition of $\mathrm{NaHCO}_{3}$ (controls in natural seawater).

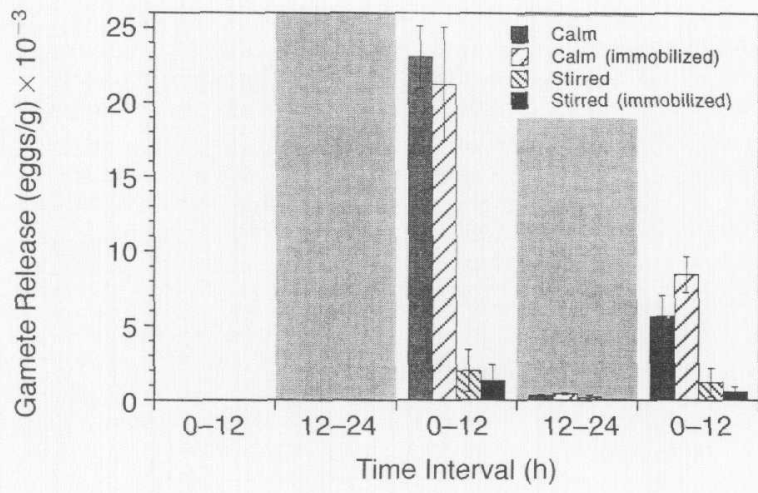

FIG. 8. Experiment to separate the effects of water motion from the movement of receptacles in the water column on gamete release in $F$. distichus. Movement of receptacles was unrestricted in the "Calm" and "Agitated" treatments, but they were held in place relative to the water flow (natural seawater) and incident light in the "Calm (immobilized)" and "Agitated (immobilized)" treatments. Gray bars show the dark part of the photoperiod (12:12 h light: dark). Values are means $\pm 1 \mathrm{SE}(n=4$ culture vessels per treatment).

water motion from secondary effects, such as changes in PFD caused by the tumbling motion of receptacles through the water, or the bumping of receptacles against each other or the walls of the culture vessels, we found that gamete release in $F$. distichus was inhibited by water motion regardless of whether receptacles were allowed to tumble freely in the seawater, or were immobilized with respect to the flow (Fig. 8). The characteristics of the flow regime generated by magnetic stirring in this experiment (Fig. 3c) differed from those experiments in which an orbital shaker was used. The mean current velocity was similar to that generated by orbital shaking $(0.32 \mathrm{~m} / \mathrm{s})$, although it varied over a much smaller range $(0.22-0.45 \mathrm{~m} / \mathrm{s})$, and showed no periodic wave-like oscillations. This amount and type

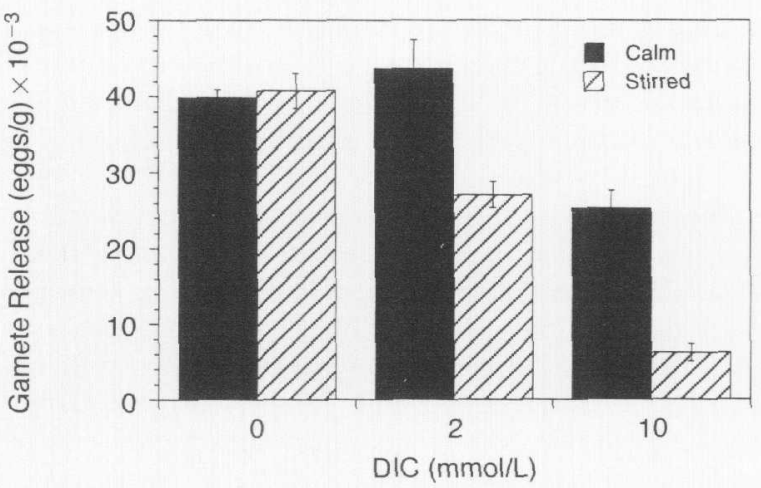

FIG. 9. Effects of dissolved inorganic carbon concentration and water motion on gamete release by receptacles of $P$. compressa. Receptacles were incubated in DIC-free, buffered seawater $(10 \mathrm{mmol} / \mathrm{L}$ Tris; $\mathrm{pH} 8.0)$, with $\mathrm{NaHCO}_{3}$ added when required. Water motion was provided by magnetic stirring plates. Values are means $\pm 1 \mathrm{SE}(n=5)$. 
of water motion was, however, effective in blocking gamete release from $F$. distichus.

The magnitude of gamete release in DIC-free seawater was independent of water motion in $P$. compressa (Fig. 9), in contrast to seawater containing 2 or 10 mmol/L of DIC at the start of the experiment, where water motion significantly decreased gamete release (ANOVA: $F_{2.24}=11.84 ; P<0.0001$ and Tukey's test for comparisons of the means). This experiment was done in completely closed culture vessels, unlike the experiment with $F$, vesiculosus. The quantity of gametes released under stirred conditions in the closed system at $2 \mathrm{mmol} / \mathrm{L}$ DIC was greater than we typically found for receptacles of the same species agitated in an open system exposed to air. The reasons for this are unclear, but were consistently observed when the experiment was repeated. In a previous experiment with $P$. compressa using an open culture system to examine the effects of water motion on gamete release, calm cultures relcased $26278 \pm 5446 \mathrm{eggs} / \mathrm{g}$ receptacle fresh mass whereas agitated cultures released $245 \pm 158$ eggs/g receptacle fresh mass (values are means $\pm 1 \mathrm{SE}$, $n=5$ ), confirming that agitation inhibits gamete release under these conditions in this species. The mean flow velocity of $0.48 \mathrm{~m} / \mathrm{s}$ was higher than, but lacked the periodicity generated by, orbital shaking (Fig. 3d; range $0.38-0.54 \mathrm{~m} / \mathrm{s}$ ). The periodic wave-like motion provided by an orbital shaker may provide greater turbulence than closed flasks with magnetic stirrers, which provide a more uniform flow rate. However, gamete release in $F$. distichus was inhibited in stirred cultures at $0.32 \mathrm{~m} / \mathrm{s}$ (Figs. $3 \mathrm{c}$ and 8 ). Alternatively, photosynthesis might deplete DIC to a significantly greater extent in the closed-compared to the open-culture system.

\section{Discussion}

In this study, we present several lines of evidence in support of the hypothesis that, with regard to the control of gamete release, water motion is sensed via changes in the rate of supply of dissolved inorganic carbon (DIC) to the reproductive tissues. Firstly, gamete release was insensitive to water motion in DICfree seawater in a closed-culture system, presumably because there was no net supply of inorganic carbon to the receptacles from the medium. In the same experiment, the predicted inhibitory effect of water motion was observed in treatments containing DIC ( 2 or $10 \mathrm{mmol} / \mathrm{L}$ ), with lower gamete release in stirred relative to calm cultures. Secondly, gamete release was inhibited to the same extent from receptacles that were immobilized relative to the flow or allowed to tumble freely in the water column, showing that factors secondarily associated with increased flow rate (e.g., motion-induced variations in PPFD) were not responsible for the observed reductions in gamete release. Thirdly, decreasing the diffusion resistance by increasing the DIC concentration under calm conditions decreased gamete release, mimicking the effects of water motion by increasing the flux of DIC to the receptacles. Our results suggest that fucoid algae possess a "physiological sensor" of hydrodynamic conditions that is coupled to the control of gamete release, a key event in the life history of organisms with external fertilization. The depletion of inorganic carbon, in the unstirred boundary layer next to the thallus in the light when water motion is low, may then provide a signal involved in triggering the release of gametes. The effects of water motion on the unstirred boundary layer are important in controlling the rates of several physiological processes in macroscopic marine organisms from macroalgae to corals, such as photosynthesis, respiration, and nutrient assimilation (e.g., Dromgoole 1978, Wheeler 1980, Koehl and Alberte 1988, Carpenter et al. 1991, Patterson et al. 1991, Shashar et al. 1993), because diffusive transport is much slower in water than in air $\left(10^{4}\right.$ times slower for $\left.\mathrm{CO}_{2}\right)$. We previously reported (Serrão et al. 1996) that gamete release in fucoid algae was inhibited by high water motion and that photosynthetic competence was necessary for normal gamete release under calm conditions. The results of this study indicate that water motion does not inhibit the production and/or maturation of gametangia, since the cumulative release of gametes from receptacles returned to calm conditions following a period of several days of agitation exceeded that from calm or simulated tidal cultures.

Fucoid algae are able to use bicarbonate, which forms $\sim 90 \%$ of the DIC in seawater, as a source of carbon for photosynthesis (Cook et al. 1986, Axelsson and Uusitalo 1988, Surif and Raven 1989, Maberly 1990 ). We found that gamete release in $P$. compressa was inversely related to $\left[\mathrm{HCO}_{3}^{-}\right]$when the relative amounts of inorganic carbon species were altered in seawater buffered between $\mathrm{pH} 7.1$ and 8.6. Periods of natural gamete release by $F$. distichus were correlated with depletion of the DIC content of the tide pools, resulting from photosynthesis during exposure of the pools during daytime low tides. Few gametes were released during nighttime low tides, resulting in a distinctly diurnal pattern of release. A pattern of gamete release coincident with that observed in the field occurred in cultured receptacles provided with a natural photoperiodic regime, saturating light for photosynthesis, and water motion simulating tidal conditions. Constant agitation of cultures, or addition of DIC during calm periods, inhibited gamete release. These results are consistent with the hypothesis that DIC limitation is the sensor for water motion as a proximate signal for gamete release in natural populations.

Environmental water motion is a proximate factor controlling gamete release in submerged populations of $F$. vesiculosus in the Baltic Sea (Serrão et al. 1996) where due to the lack of tides, there are no predictable cycles of calm and turbulent conditions comparable to tide pools. Rather, water motion is wind-driven and therefore unpredictable both in time and from site to 
site. Baltic water is $\sim \mathrm{pH} \&$ in the central Baltic Sea, but within $F$. vesiculosus beds during a calm day it may exceed $\mathrm{pH} 9.0$ (Serrão 1996). In this environment, the rate of DIC supply to cells may provide a very sensitive and reliable indicator of environmental water motion. Variations in the hydrodynamic regime greatly influence inorganic carbon supply at low current velocities, by altering the thickness of the diffusive boundary layer (Wheeler 1980, Koehl and Alberte 1988, Hurd and Stevens 1997); in zero flow, photosynthetic rates are reduced by $29 \%$ in the green alga Ulva lactuca (Koch 1993), and between 30 and 50\% in the red alga Gracilaria conferta (Gonen et al. 1993). The mean flow velocitics of between 0.30 and $0.48 \mathrm{~m} / \mathrm{s}$ used in our experiments effectively inhibited gamete release in the three species of fucoid algae tested, both under oscillatory flow generated by orbital shaking, or under more constant flow conditions generated by stirring. Oscillatory flows (of greater wavelength) producing pressure waves are more typical of marine environments (e.g., Kochl 1977); however, with regard to gamete release, the importance of flow appears to be in controlling the rate of supply of DIC to receptacles. Carbon fixation is a sink for electrons generated by the photochemical reactions of photosynthesis; thus, several feedback mechanisms, either at the photochemical level, at the level of the photosynthetic carbon reduction pathway, or in response to alterations in cellular energy balance, could be initiated by changes in the rate of supply of DIC, thereby linking environmental signals to intracellular controls of gamete release. Other effects of altered DIC (i.e.. not related to photosynthesis) could infuence intracellular signaling because of the central role of $\mathrm{HCO}_{3}$ in metabolism (e.g., Sperelakis 1995); however, our data (Serrão et al. 1996) support a direct role for photosynthetic metabolism in the feedback mechanism.

The ecological significance of a mechanism for sensing water motion based on DIC is less clear for intertidal species that are emersed during low tide. but that experience turbulent flows when immersed. Since water velocities of only $0.02-0.08 \mathrm{~m} / \mathrm{s}$ are required to overcome DIC limitation due to the diffusive boundary layer in other algal species (Gonen et al. 1993, Koch 1993), and the transition from a laminar to a turbulent velocity boundary layer in kelps and fucoids occurs at mainstream velocities of $0.015-0.03 \mathrm{~m} / \mathrm{s}$ (Hurd and Stevens 1997), water motion may be too high to result in DIC limitation during typical days on exposed shores. This suggests the potential importance of (1) unusually calm days, (2) the reduction in bulk water flow experienced by some benthic organisms (e.g., Koehl 1977, Koehl and Alberte 1988, Brawley 1992) due to aggregation of individuals, morphology, etc, and/or (3) release or priming of release of gametes during emersion at low tide, which may still be based on DIC supply. Published data on rates of carbon fixation in emersed fucoid algae suggest that photosyn- thesis is not carbon saturated in air (e.g., Surif and Raven 1990); some authors have found rates comparable to, or slightly greater than submersed photosynthesis (Johnson et al. 1974, Quadir et al. 1979, Johnston and Raven 1986), whereas others have found much reduced rates in air (Bidwell and Craigic 1963). Several factors are likely to influence acrial photosynthesis in situ, including the thickness of the water film surrounding the thallus (affecting the diffusive distance for $\mathrm{CO}_{2}$ ) and the degree of shading due to other individuals or orientation of the thallus to the incident light. Gametc release by intertidal fucoid species (i.e.. F. vesiculosus, $P$. compressa) was inhibited by water motion and stimulated by low DIC in our experimental studies, in a similar way to $F$. distichus, and gamete release at low tide has been observed in many intertidal fucoids, including P. compressa (e.g., Brawley 1990). Thus, it will be important for future studies to investigate in situ the ecological significance of the response to DIC for gamete release and the reproductive ecology of intertidal species by comparing the magnitude of viable gamete release and fertilization during different intervals within a tidal cycle.

An unanswered question about the timing of gamete release in fucoids is whether it is a response to environmental variations associated with changing tidal phase, or whether there is an endogenous component to these semilunar rhythms. If an endogenous component is involved, it would be of interest to know what entraining factors, or zeitgebers, are involved (Müller 1962, Franke 1985). Receptacles of $F$. distichus brought into culture from the field exhibited peak gamete release coincident with natural populations, even in calm conditions in constant light (see Results). However, months-long studies in culture will be necessary in order 10 demonstrate whether or not intrinsic rhythms are involved (e.g., cycles of gametangial maturation).

Respiration and/or photosynthesis modify the properties of the diffusive boundary layer surrounding many sessile and slow-moving marine organisms, and these processes are sensitive to small changes in water motion. In addition to the effects of water motion on a varicty of marine algae, there are well-known effects on the metabolism of corals. The respiration rates of reef-building corals are dependent on oxygen and $\mathrm{pH}$ profiles in the boundary layer; flow rate can limit respiration in darkness, and may limit polyp size (Shashar et al. 1993), whereas the photosynthetic activity of endosymbiotic zooxanthellae can increase respiration up to six-fold in saturating irradiances (Kühl et al. 1995). Thus, the potential for the detection of hydrodynamic conditions via changes in physiological state exists in many marine species, and spawning mechanisms that take advantage of this ability may be more widespread than currently realized. It is interesting in this context that in situ observations of the spawning of corals have noted that very low current velocities often prevail dur- 
ing gamete release (Babcock et al. 1986, Fadlallah 1996).

Our results suggest that key events in the life history of a species, such as the success of fertilization, can depend upon physiological processes (e.g., photosynthesis); these may, therefore, have impacts on the fitness of adults that are independent from their effects on growth, productivity, or stress tolerance. This independent source of selective pressure on physiological traits should be particularly important in organisms such as fucoid algac that inhabit stressful environments and lack asexual reproduction. The ability of fucoid algae to couple a hydrodynamic sensing mechanism with gamete release has led to a high potential to synchronize the timing of gamete release, and consequently to enhance the success of external fertilization.

\section{ACKNOWLFDGMENTS}

We would like to thank Tim Miller and the staff at the Darling Marine Center. for providing facilities and help during field work and experiments with Fucus distichus. This work was supported by NSF awards OCE 92-1698I and IBN9604848 to SHB. Comments by two anonymous reviewers and R. K. Grosberg improved the manuscript.

\section{LITERATCRI: CITED}

Axelsson. L.. and J. Lusitalo. 1988. Carbon acquisition strat egies for marine macroalgae. 1. Utilization of proton exchanges visualized during photosynthesis in a closed system. Marine Biology 97:295-300.

Babcock. R. C. G. D. Bull. P. L. Harrison, A. J. Heyward. J. K. Oliver, C. C. Wallace, and B. L. Willis. 1986. Synchronous spawning of 105 scleractinian coral species on the Great Barrier Reef. Marine Biology 90:379-394.

Babcock. R. C., C. Mundy, J. Keesing, and J. Oliver. 1992. Predicable and unpredictable spawning events: in situ behavioral data from free-spawning coral reef invertebrates. [nvertebrate Reproduction and Development 22:213-228.

Beach. D. H.. N. J. Hanscomb. and R. F. G. Ormond. 1975. Spawning pheromone in crown-of-thorns starfish. Nature 254: $135-136$.

Bidwell. R. G, S. and J. S. Craigie. 1963. A note on the greatly reduced ability of Fucus vesiculosus to absorb or evolve $\mathrm{CO}_{2}$ when not submerged. Canadian Journal of Botany 41:179-182.

Bird. V. L... and J. McLachlan. 1976. Control of formation of receptacles in Fucus distichus L. subsp. distichus (Phaeophyceae, Fucales). Phycologia 15:79-84.

Brawley. S. H. 1990. Polyspermy blocks in fucoid algae and the occurrence of polyspermy in nature. Pages $419-431$ in B. Dale. editor. Mechanism of fertilization. Springer-Verlag. Berlin. Germany.

- 1992. Fertilization in natural populations of the dioecious brown alga Fucus ceranoides and the importance of the polyspermy block. Marine Biology 113:145-157.

Brawley. S. H.. and L. E. Johnson. 1992. Gametogenesis. gametes and zygotes: an ecological perspective on sexual reproduction in algae. British Phycological Journal 27:233252

Carpenter. R. C.. J. M. Hackney, and W. H. Adey. 1991 Measurements of primary productivity and nitrogenase activity of coral recf algae in a chamber incorporating oscillatory flow. Limnology and Oceanography 36:40-49.

Chapman. A. R. O.. and C. R. Johnson. 1990. Disturbance and organization of macroalgal assemblages in the Northwest Allantic. Pages $77-121 \mathrm{in} \mathrm{A.} \mathrm{R.} \mathrm{O.} \mathrm{Chapman} \mathrm{and} \mathrm{A.}$ J. Underwood. editors. Determinants of structure in inter- tidal and subtidal macroalgal assemblages. Kluwer. Dordrecht, The Netherlands.

Cook. C. M.. T. Lanaras. and B. Colman. 1986. Evidence for bicarbonate transport in species of red and brown macrophytic marine algae. Journal of Experimental Botany 37 : 977-984

Denny. M. W. 1988. Biology and the mechanics of the waveswept environment. Princeton Lniversity Press. Princeton. New Jersey. USA

Denny, M. W. J. Diariki and S. Distefano. 1992. Biological consequences of topography on wave-swept rocky shores. I. Enhancement of external fertilization. Biological Bulletin 183: $220-232$.

Denny, M. W. and M. F. Shibata. 1989. Consequences of surt-zone turbulence for settlement and external fertilization. American Naturalist 134:859-889.

Dromgoole, F. I. 1978. The effects of oxygen on dark respiration and apparent photosynthesis of marine macro-algac. Aquatic Botany 4:281-297.

Fadlallah. Y. H. 1996. Synchronous spawning of Acropora clathrata coral colonies from the western Arabian Gulf (Saudi Arabia). Bulletin of Marine Science 59:209-216.

Forster. R. M.. and M. J. Dring. 1992. Interactions of blue light and organic carbon supply in the control of lightsaturated photosynthesis in brown algae. Plant. Cell and Environment 15:241-247.

Franke, H.-D. 1985. On a clocklike mechanism timing lunarrhythmic reproduction in Typosyllis prolifera (Polychacta). Journal of Comparative Physiology, Series A 156:553-561.

Fritsch, F. E. 1945. The structure and reproduction of the algae. Volume 2. Cambridge University Press. Cambridge, $\mathrm{UK}$.

Giese, A. C., and H. Kanatani. 1987. Maturation and spawning. Pages 251-329 in A. C. Giese. J. S. Pearse. and V. B. Pearse, editors. Reproduction of marine invertebrates. Blackwell Scientific/The Boxwood Press. Palo Alto/Pacific Grove, California, USA.

Gonen, Y., E. Kimmel, and M. Friedlander. 1993. Effect of relative water motion on photosynthetic rate of red alga Gracilaria conferta. Pages 493-498 in A. R. O. Chapman. M. T. Brown, and M. Lahaye. editors. Fourteenth International Seaweed Symposium. Kluwer. Dordrecht. The Netherlands.

Guiry. M. D.. and E. M. Cunningham. 1984. Photoperiodic and temperature responses in the reproduction of northeastern Atlantic Gigartina acicularis (Rhodophyta: Gigartinales). Phycologia 23:357-367.

Hamel. J.-F. and A. Mercicr. 1996. Evidence of chemical communication during the gametogenesis of holothuroids. Ecology 77:1600-1616.

Hurd, C. L., and C. L. Stevens. 1997. Flow visualization around single- and multiple-bladed seaweeds with various morphologies. Journal of Phycology 33:360-367.

Jaffe. L. F. 1954. Stimulation of the discharge of gametangia from a brown alga by a change from light to darkness. Nature 174:743.

Johnson. W. S.. A. Gigon. S. L. Gulman, and H. A. Mooney. 1974. Comparative photosynthetic capacitics of intertidal algae under exposed and submerged conditions. Ecology 55:450-453.

Johnston. A. M. and I. A. Raven. 1986. The analysis of photosynthesis in air and water of Ascophy/hm nodosum (L.) Le Jol. Occologia 69:288-295.

Kerby, N. W., and J. A. Raven. 1985. Transport and fixation of inorganic carbon by marine algae. Advances in Botanical Research 11:71-123.

Koch. E. W. 1993. The effect of water flow on photosynthetic processes of the alga Ulia lactuca L. Pages $457-462$ in A. R. O. Chapman, M. T. Brown, and M. Lahaye, editors. 
Fourteenth International Scaweed Symposium. Kluwer, Dordrecht, The Netherlands.

Koehl, M. A. R. 1977. Effects of sea anemones on the flow forces they encounter. Journal of Experimental Biology 69: $87-105$

Koehl. M. A. R., and R. S. Alberte. 1988. Flow, flapping and photosynthesis of Nereocystis luetheana: a functional comparison of undulate and flat blade morphologies. Ma rine Biology 99:435-444

Korringa, P. 1947. Relations between the moon and periodicity in the breeding of marine animals. Ecological Monographs 17:347-381.

Küh1, M. Y. Cohen, T. Dalsgaard, B. B. Jørgensen, and N P. Revsbech. 1995. Microenvironment and photosynthesis of zooxanthellae in scleractinian corals studied with microsensors for $\mathrm{O}_{2}, \mathrm{pH}$ and light. Marine Ecology Progress Series 117:159-172.

Larsson, C.. L. Axclsson, H. Ryberg and S. Beer. 1997. Photosynthetic carbon utilization by Enteromorpha intestinalis 1Chlorophyta) from a Swedish rockpool. European Journal of Phycology 32:49-54

Lasker. H. R.. D. A. Brazeau, J. Calderon, M. A. Coffroth. R. Coma, and K. Kim. 1996. In situ rates of fertilization among broadcast spawning gorgonian corals. Biological Bulletin 190:45-55.

Ievitan. D. R., M. A. Sewell and F.-S. Chia. 1992. How distribution and abundance influence fertilization success in the sea urchin Strongylocentrotus franciscanus. Ecology $73: 248-254$

Lüning. K.. and D. G. Müller. 1978. Chemical interaction in sexual reproduction of several Laminariales (Phaeophyceae): release and attraction of spermatozoids. Zeitschrift für Pflanzenphysiologie 89:333-341.

Maberly. S. C. 1990. Exogenous sources of inorganic carbon for photosynthesis by marine macroalgae. Journal of Phycology 26:439-449.

- 1992. Carbonate ions appear to neither inhibit nor stimulate use of bicarbonate ions in photosynthesis by U/va lactuca. Plant. Cell and Environment 15:255-260.

Maier. I. 1993. Gamete orientation and induction of gametogenesis by pheromones in algae and plants. Plant, Cell and Environment 16:891-907.

Maier. I., and D. G. Müller. 1986. Sexual pheromones in algae. Biological Bulletin 170:145-175.

Mead, K. S., and M. W. Denny. 1994. The effects of hydrodynamic shear stress on fertilization and early development of the purple sea urchin Strongylocentrotus purpuratus. Biological Bulletin 188:46-56.

Miller. R. L. 1989. Evidence for the presence of sexual pheromones in free-spawning starfish. Journal of Experimental Marine Biology and Ecology 130:205-221.

Müller. D. G. 1962. Über jahres- und lunarperiodische Erscheinungen hei einigen Braunalgen. Botanica Marina 4: $140-155$

Müller. D. G., I. Maier, and G. Gassmann. 1985. Survey on sexual pheromone specificity in Laminariales (Phaeophy ceae). Phycologia 24:475-477.

Neumann. D. 1987. Tidal and lunar rhythmic adaptations of reproductive activities in invertebrate species. Pages 152 170 in P. Pévet. editor. Tide, moon, magnetic field and rhythmic functions. Karger, Basel. Switzerland.

Oliver. J., and R. Babcock. 1992. Aspects of the fertilization ecology of broadcast spawning corals: sperm dilution effects and in situ measurements of fertilization. Biological Bulletin 183:409-417.

Patterson. M. R., K. P. Sebens, and R. R. Olsen. 1991. In situ measurements of How effects on primary production and dark respiration in reef corals. Limnology and Oceanography 36:936-948.
Pearson, G. A., and S. H. Brawley. 1996. Reproductive ecology of Fucus distichus (Phaeophyceae): an intertidal alga with successful external fertilization. Marine Ecology Progress Series 143:211-223.

Pennington, J. T. 1985. The ecology of fertilization of echinoid eggs: the consequences of sperm dilution, adult aggregation, and synchronous spawning. Biological Bulletin 169:417-430.

Petersen. C. W. 1991. Variation in fertilization rate in the tropical reef fish, Halichoeres bivattatus: correlates and implications. Biological Bulletin 181:232-237.

Petersen, C. W. R. R. Warner, S. Cohen, H. C. Hess, and A. T. Sewell. 1992. Variable pelagic fertilization success: im plications for mate choice and spatial patterns of mating. Ecology 73:391-401

Phillips, J. A., M. N. Clayton, I. Maier. W. Boland, and D. G. Müller. 1990. Sexual reproduction in Dictyota diemensis (Dictyotales. Phaeophyta). Phycologia 29: $367-379$

Quadir, A.. P. J. Harrison, and R. E. DeWreede. 1979. The effects of emergence and submergence on the photosynthesis and respiration of marine macrophytes. Phycologia 18:83-88.

Rice, E. L.. and A. R. O. Chapman. 1985. A numerical taxonomic study of Fucus distichus L. emend. Powell (Phaeophyta). Journal of the Marine Biological Association of the U.K. 65:433-459.

Robertson, D. R., C. W. Petersen, and J. D. Brawn. 1990 Lunar reproductive cycles of benthic-brooding reef fishes: reflections of larval biology or adult biology? Ecological Monographs 60:311-329.

Santelices, B. 1990. Patterns of reproduction, dispersal and recruitment in seaweeds. Oceanography and Marine Biology Annual Review 28:177-276.

Serrão, E. A. 1996. Reproductive ecology of Fucus vesiculosus 1. in the Baltic Sea. Dissertation. University of Maine. LSA.

Serrão, E. A., G. A. Pearson, L. Kautsky, and S. H. Brawley. 1996. Successful external fertilization in turbulent environments. Proceedings of the National Academy of Sciences (USA) 93:5286-5290.

Shashar, N., Y. Cohen, and Y. Loya. 1993. Extreme diurnal fluctuations of oxygen in diffusive boundary layers sur rounding stony corals. Biological Bulletin 185:455-461.

Silva, P. C. 1996. California seaweeds collected by the Malaspina expedition, especially Pelvetia (Fucales, Phaeophy ceae). Madroño 43:345-354.

Skirrow, G, 1975. The dissolved gases-carbon dioxide Pages 1-192 in J. P. Riley and G. Skirrow, editors. Chemical oceanography. Volume 2. Academic Press, New York, New York, USA.

Sperelakis, N. 1995. Cell physiology source book. Academic Press, San Diego, California. USA.

Starr, M., J. H. Himmelman, and J.-C. Therriault. 1990. Di rect coupling of marine invertebrate spawning with phytoplankton blooms. Science 247:1071-1074

Starr, M., J. H. Himmelman, and J.-C. Therriault. 1993. Environmental control of green sea urchin. Strongylocentrotus droebachiensis, spawning in the St. Lawrence estuary. Canadian Journal of Fisheries and Aquatic Sciences 50:894901

Strickland. J. D. H., and T. R. Parsons. 1972. A practical handbook of seawater analysis. Fisheries Board of Canada, Ottawa, Canada.

Surif, M. B., and J. A. Raven. 1989. Exogenous inorganic carbon source for photosynthesis in seawater by members of the Fucales and Laminariales (Phaeophyta): ecological and taxonomic implications. Oecologia 78:97-105

Surif, M. B., and J. A. Raven. 1990. Photosynthetic gas 
exchange under emersed conditions in eulittoral and normally submersed members of the Fucales and the Laminariales: interpretation in relation to $\mathrm{C}$ isotope ratio and $\mathrm{N}$ and water use efficiency. Oecologia 82:68-80.

Wheeler, W. N. 1980. Effect of boundary layer transport on the fixation of carbon by the giant kelp Macrocystis pyrifera. Marine Biology 56:103-110.

Williams, J. L. 1905. Studies in the Dictyotaccae. III. The periodicity of the sexual cells in Dictyota dichotoma. Annals of Botany 19:531-560. 